\title{
Propagation, linkage, and interaction of caldera ring-faults: comparison between analogue experiments and caldera collapse at Miyakejima, Japan, in 2000
}

\author{
Steffi Burchardt • Thomas R. Walter
}

Received: 9 December 2008 / Accepted: 24 August 2009 /Published online: 6 October 2009

(C) The Author(s) 2009. This article is published with open access at Springerlink.com

\begin{abstract}
The formation of ring faults yields important implications for understanding the structural and dynamic evolution of collapse calderas and potentially associated ash-flow eruptions. Caldera collapse occurred in 2000 at Miyakejima Island (Japan) in response to a lateral intrusion. Based on geophysical data it is inferred that a set of caldera ring faults was propagating upward. To understand the kinematics of ring-fault propagation, linkage, and interaction, we describe new laboratory sand-box experiments that were analyzed through Digital Image Correlation (DIC) and post-processed using $2 \mathrm{D}$ strain analysis. The results help us gain a better understanding of the processes occurring during caldera subsidence at Miyakejima. We show that magma chamber evacuation induces strain localization at the lateral chamber margin in the form of a set of reverse faults that sequentially develops and propagates upwards. Then a set of normal faults initiates from tension fractures at the surface, propagating downwards to link with the reverse faults at depth. With increasing amounts of subsidence, interaction between the reverse- and normalfault segments results in a deactivation of the reverse faults,
\end{abstract}

Communicated by J. Stix

Electronic supplementary material The online version of this article (doi:10.1007/s00445-009-0321-7) contains supplementary material, which is available to authorized users.

S. Burchardt $(\bowtie)$

Geoscience Center of the Georg-August-University of Göttingen, Goldschmidtstr. 1,

Göttingen 37077, Germany

e-mail: sburcha@gwdg.de

T. R. Walter

Helmholtz-Zentrum Potsdam Deutsches

GeoForschungsZentrum (GFZ),

Telegrafenberg,

Potsdam 14473, Germany while displacement becomes focused on the outer normal faults. Modeling results show that the area of faulting and collapse migrates successively outward, as peak displacement transfers from the inner ring faults to later developed outer ring faults. The final structural architecture of the faults bounding the subsiding piston-like block is hence a consequence of the amount of subsidence, in agreement with other caldera structures observed in nature. The experimental simulations provide an analogy to the observations and seismic records of caldera collapse at Miyakejima volcano, but are also applicable to caldera collapse in general.

Keywords Collapse calderas · Ring faults · Analogue modeling $\cdot$ Fault kinematics $\cdot$ Digital image correlation

\section{Introduction}

Collapse calderas are kilometer-scale volcanic depressions bordered by ring faults that form during the evacuation of crustal magma chambers (Williams 1941). Evacuation may be due to lateral intrusion into the host rock or due to upward eruption along conduits or faults, initiating subsidence of the magma-chamber roof and caldera floor (Smith and Bailey 1968). Understanding the link between eruption dynamics and caldera subsidence requires knowledge of the structural progression, including the development and changing location of the active near-surface and underground faults.

Caldera volcanoes exist in nearly all tectonic settings (Newhall and Dzurisin 1988), and may be associated with the largest explosive eruptions known on Earth (Druitt and Sparks 1984). During the last 100 years, however, explosive eruptions at calderas have been of moderate size; 
fewer than $5 \%$ have reached a VEI $>4$ eruption (Newhall and Dzurisin 1988). Calderas at basaltic volcanoes experience collapse, which is not necessarily associated with major eruption volumes (e.g. Mauna Loa, Fernandina, Piton de la Fournaise, and Miyakejima). However, the structural inventory, such as the configuration of associated ring faults and dikes, is similar for silicic and basaltic volcanoes including near-vertical or variously dipping faults.

Geological and geophysical studies of caldera volcanoes suggest contrasting details of caldera fault architectures (e.g. Smith and Bailey 1968, Lipman 1984, 1997). Experimental studies generally produce several sets of outward-dipping reverse faults and steeply inward-dipping, peripheral normal faults during a single collapse event (e.g. Roche et al. 2000; see section "Digital image processing results" and Supplementary Material S1) demonstrating that the different structures found in the field can coexist. In contrast, most numerical simulations fail to predict reverse faults (e.g. Folch and Marti 2004; Gray and Monaghan 2004; see Supplementary Material S1).

The caldera collapse associated with the 2000 Miyakejima lateral dike intrusion and magma chamber deflation is probably the best instrumentally recorded caldera forming event. Deformation and seismicity records, as well as observations of eyewitnesses, allow a detailed investigation into the chronology of events, showing sequentially upward propagating faults and depression widening near the surface (Geshi et al. 2002; Nakada et al. 2005). In this paper, we first examine the progression of caldera formation at Miyakejima. Then we compare it with the results of laboratory simulations analyzed with a digital image correlation technique. The experiments give sub-millimeter deformation time-series, providing new insights into the variable propagation and linkage of ring faults and revealing the structural complexity of calderas.

\section{The Miyakejima caldera collapse sequence}

Miyakejima Island is a $9 \mathrm{~km}$ wide, $815 \mathrm{~m}$ high inhabited island located to the southeast of Honshu, Japan. Volcanic activity on Miyakejima has been observed frequently in 1874, 1940, 1962, and 1983 (Tsukui et al. 2001). The island's morphology has been shaped by repeated explosive eruptions, some associated with caldera collapse (e.g. 2,500 years ago), others with effusive fissure eruptions on the flanks (GVP). In summer 2000 a new, $1.7 \mathrm{~km}$ wide caldera developed at the summit of Miyakejima, the floor of which subsided to a depth of $250 \mathrm{~m}$ above sea level, giving a cumulative subsidence of 1.6 to $2.1 \mathrm{~km}$ (Geshi et al. 2002).

The 2000 Miyakejima caldera collapse sequence began at the end of June with seismicity and deformation occurring tens of kilometers northwest of Miyakejima
Island. The seismicity pattern as shown in Fig. 1 is related to dike intrusion away from Miyakejima, with an aftershock sequence that resembled a partial "butterfly" pattern that could be explained by stress transfer in the shallow crust (Toda et al. 2002). Dike intrusion resulted in drainage of the magma reservoir underlying the volcano (Fig. 2), estimated to be at a depth of 4 to $5 \mathrm{~km}$ below sea level (Furuya et al. 2001; Nakada et al. 2001). In the beginning of July, a columnar earthquake swarm with a diameter of $2 \mathrm{~km}$ (Sakai et al. 2001) was initiated deep beneath the summit.

Seismic data recorded and processed by the Earthquake Research Institute, University of Tokyo (ERI), suggest a sequential upward propagation of earthquakes during caldera subsidence (Sakai et al. 2001; Geshi et al. 2002). As shown in Fig. 3, the upward propagation of seismicity is bracketed by the time interval between lateral dike intrusion and surface caldera formation. Associated with this apparently upward migration of active faulting, the magnitude (Fig. 3a, b) and cumulative number of earthquakes increased (Fig. 3c), followed by an increase in the cumulative moment release. On 8 July slight flexural subsidence of the summit of Miyakejima volcano was transformed into the collapse of a caldera. The surface expression of the caldera was thus delayed with respect to drainage of the underlying reservoir (Fig. 1b), which was explained by successive upward fault propagation and underground collapse before reaching the surface (Walter and Troll 2001; Geshi et al. 2002). Caldera collapse was associated with explosive eruptions that occurred during the following month, climaxing on 18 August 2000 and migrating from the center of the newly-formed caldera to its margin (Geshi and Oikawa 2008). According to Geshi et al. (2002), the newly formed caldera consisted of a central piston, $300 \mathrm{~m} \times 500 \mathrm{~m}$ large, surrounded by a concentric array of tension fractures and normal faults with an overall diameter of $1 \mathrm{~km}$. After two days of subsidence, the caldera depression had reached a depth of $300 \mathrm{~m}$. During the following month, the diameter of the caldera depression continually increased to a final diameter of $1.6 \mathrm{~km}$, accompanied by the occurrence and retreat of new faults at the surface and slumps of large blocks into the depression. Due to gravitational collapse of the caldera wall, the depth of the depression remained constant $(450 \mathrm{~m})$ from the middle of July on. The effective amount of subsidence was between 1.6 and $2.1 \mathrm{~km}$; thus, the original caldera floor subsided to a depth below sea level, with a structural diameter smaller than the topographic diameter (Geshi et al. 2002). Based on the assumption that the size of the magma reservoir corresponds to the diameter of the subsiding piston and that the magma chamber was situated at $3 \mathrm{~km}$ depth (Geshi et al. 2002), the resulting aspect ratio $(\mathrm{AR}=$ depth to the magma 


\section{A) Seismicity prior to caldera collapse}

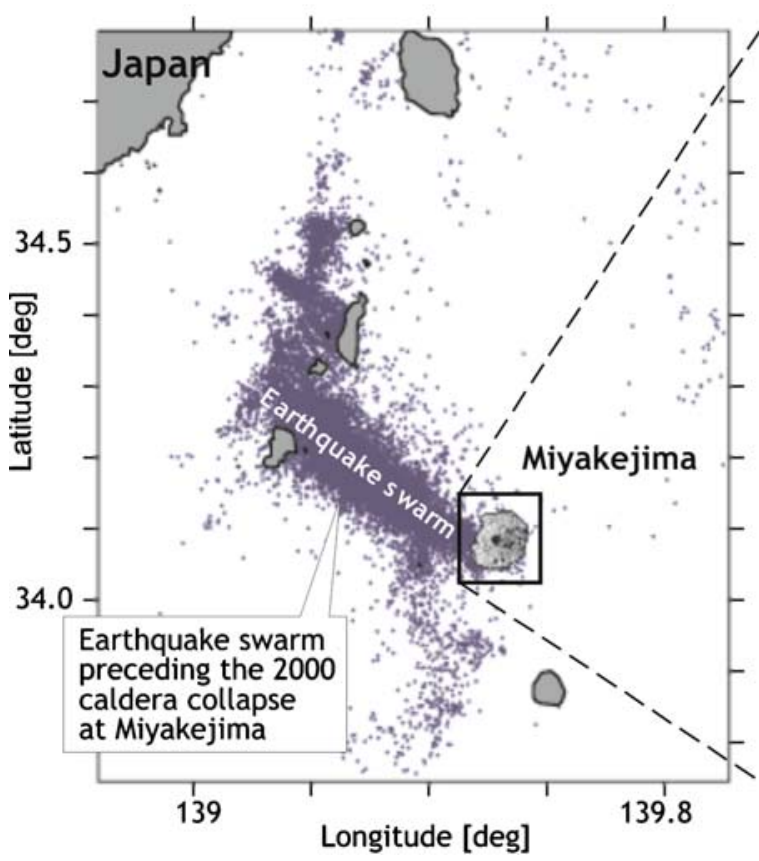

Fig. 1 a Distribution of seismic events preceding the 2000 caldera collapse on Miyakejima Island, Japan (Toda et al. 2002; data from ERI, Earthquake Research Center, University of Tokyo). The earthquake swarm migrating offshore from Miyakejima to the NW was related to dike injection (Yamaoka et al. 2005). b SAR images of the formation of a collapse caldera at the summit of Miyakejima

chamber roof divided by its diameter) of the Miyakejima caldera is in the range of about 2.5 (Geshi, pers. communication).

Structural architecture and kinematics of ring-faults

In spite of these detailed observations on Miyakejima Island, the geometric evolution and kinematics of ring

\begin{tabular}{|c|c|c|c|}
\hline June & July & August & September 2000 \\
\hline \multicolumn{3}{|c|}{ Offshore earthquake swarm } \\
Earthquakes beneath the summit of Miyakejima \\
\cline { 2 - 3 } Caldera collapse \\
Intrusion & Caldera formation & Explosion & Degassing \\
\hline
\end{tabular}

Fig. 2 Chronology of the events related to caldera collapse at Miyakejima volcano according to Geshi et al. (2002) and Nakada et al. (2005). An intrusion stage in the beginning led to the injection of a dike and a submarine eruption (marked by dark grey star) to the NW of the volcano. This was followed by caldera collapse from 8 July to mid-August accompanied by stronger explosive activity (indicated by light grey stars). By the end of August, activity switched to strong degassing from the summit of Miyakejima
Island, Japan, in 2000. Magma chamber deflation preceded caldera subsidence by 2 weeks. As a result, a small caldera formed on July 8 . This caldera widened considerably during continuing subsidence by the formation of peripheral normal faults and landslides. Images provided by Japanese National Institute of Information and Communications Technology (NICT), 2007

faults, including fault propagation and interaction, are still incompletely understood. Despite years of vigorous debate, there is not yet a consensus on whether caldera faults at Miyakejima and elsewhere are inward- or outward-dipping (e.g., Gudmundsson and Nilsen 2006; Acocella 2007) since there is field evidence for both structures. New eruptions may initiate from faulting of magma chamber roofs, such as hypothesized for Miyakejima. Thus, the propagation direction of ring faults, as well as their interaction, are of major importance for understanding syn-collapse eruption locations and vent dynamics (e.g. Geshi and Oikawa 2008; Holohan et al. 2008), syn-collapse magma-chamber dynamics (Kennedy et al. 2008), conduit widening, sites for post-collapse volcanism (e.g. Saunders 2001), geothermal activity (e.g. Goff et al. 2000), and mineralization (e.g. Stix et al. 2003).

Laboratory experiments on caldera formation above a deflating magma-chamber analogue (see recent reviews by Cole et al. 2005; Acocella 2007, 2008; Marti et al. 2008; and references therein) suggest that caldera collapse generates two sets of ring structures, an inner set of outward-dipping reverse ring faults enclosed by a second set of inward-dipping normal faults (cf. Appendix S1). Field and geophysical data, however, suggest various expressions of those ring fault architectures; outward- and 

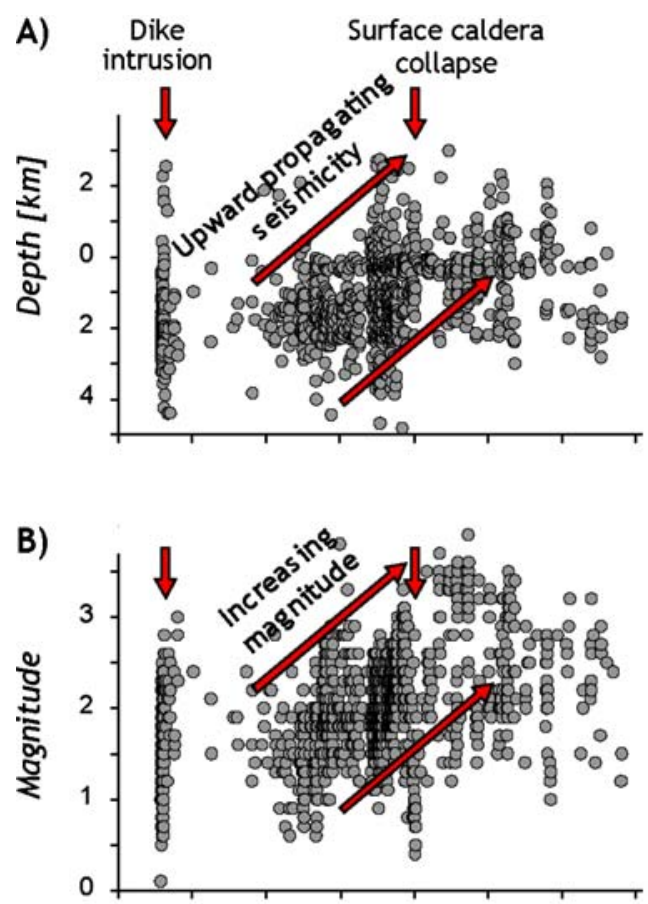

C)

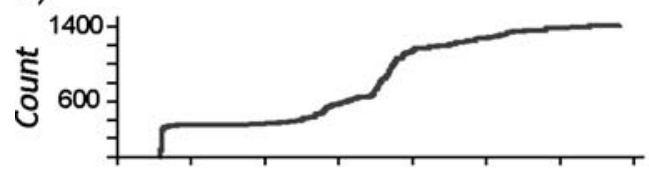

D)

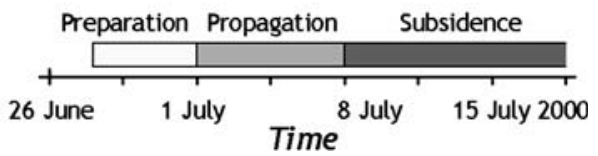

Fig. 3 Seismic activity at Miyakejima Island beneath the summit associated with the caldera collapse in 2000. Data from Sakai et al. (2001). a The depth distribution of epicenters shows a distinct upwards propagation with time after the dike intrusion at the end of June. b The magnitude of earthquakes increased with time before caldera collapse. c Cumulative number of earthquakes beneath Miyakejima. After dike intrusion NW of Miyakejima Island, the number of seismic events increased strongly until shortly before caldera collapse. Note that not all seismic events have been picked due to their great number and since smaller events on Miyakejima Island were often overlain by larger events offshore ( $\mathrm{T}$. Ohminato, personal communication 2008). d The temporal and spatial distribution of seismicity is characterized by a multi-phase pattern that can be divided into (1) a Preparation Phase with very low seismic activity; (2) a Propagation Phase with high seismic activity migrating upwards; and (3) a Subsidence Phase with moderate seismicity without clear migration

inward-dipping ring faults are evident at Rabaul, Papua New Guinea (Mori and McKee 1987), whereas caldera collapse at Fernandina, Galapagos in 1968 apparently occurred along inward-dipping ring faults (Simkin and Howard 1970), a configuration also known from eroded calderas in the Western USA (Lipman 1984). While inward-dipping ring faults may cause a "space problem" during subsidence to prohibit major conduit opening (Branney 1995), outward-dipping faults are rarely observed at the surface due to landslide processes (Lipman 1984). In some caldera systems, contemporaneous sub-parallel ring faults appear to provide magma pathways, e.g., Deception and Rabaul (Newhall and Dzurisin 1988), implying that the faults develop progressively and that at times more complex configurations of ring faults may be active.

In order to better understand the structural and temporal evolution of caldera subsidence at Miyakejima and other basaltic (and silicic) volcanoes, as well as to clarify the link between surface expression and deep structural framework of calderas, we present new experimental results analyzed with the aid of a high-resolution digital recording technique. Our results show the dynamic evolution of ring-fault formation, propagation and interaction, and also demonstrate the ability to quantify the kinematics of these processes, as detailed in the next section.

\section{Analogue experiments}

Experimental setup and scaling

We follow previous experimental investigations (e.g. Roche et al. 2000), simulating caldera subsidence and shear localization in a granular material that approaches a MohrCoulomb friction law (Schellart 2000). Our new results comprise application of a digital image correlation (DIC) technique that allows strain studies with spatial and dynamic resolutions in sub-millimeter and microstrain range, respectively (Adam et al. 2005). A monochrome CCD (charge-coupled device) digital camera was used to acquire images at high resolution (12 megapixels). Calculation of displacements at precisions of $<0.1$ pixels (White et al. 2001) was achieved by the application of a multi-pass cross correlation algorithm (LaVision 2002), allowing us to compare successive images. We compared the particle distribution of two subsequent images in order to derive the deformation-vector field and the strain field in each granular flow experiment (Fig. 4). For the adopted distance to the experiment box and camera parameters, we obtained spatial resolutions of about $0.2 \mathrm{~mm}$ and a temporal resolution between successive images of $5 \mathrm{~Hz}$. Further details about the DIC method are provided in the Electronic Supplementary Material (S3).

The experiments were performed in a sand box, and cross-sectional development could be investigated through two glass panes set up at a distance of $10 \mathrm{~cm}$ (Fig. 4). To simulate reservoir deflation, we used a retractable piston with an area of $10 \times 10 \mathrm{~cm}^{2}$ emplaced within a cut-out of the same size in the basal plate. At the beginning of the 
Fig. 4 a Schematic sketch of the experimental setup. The space between the two glass panes was filled to different depths with a mixture of starch and sand to simulate different roof aspect ratios. The piston was retracted $1.8 \mathrm{~cm}$. b Schematic sketch of the Digital Image Correlation (DIC) method adapted from http://www.lavision.de/
A)

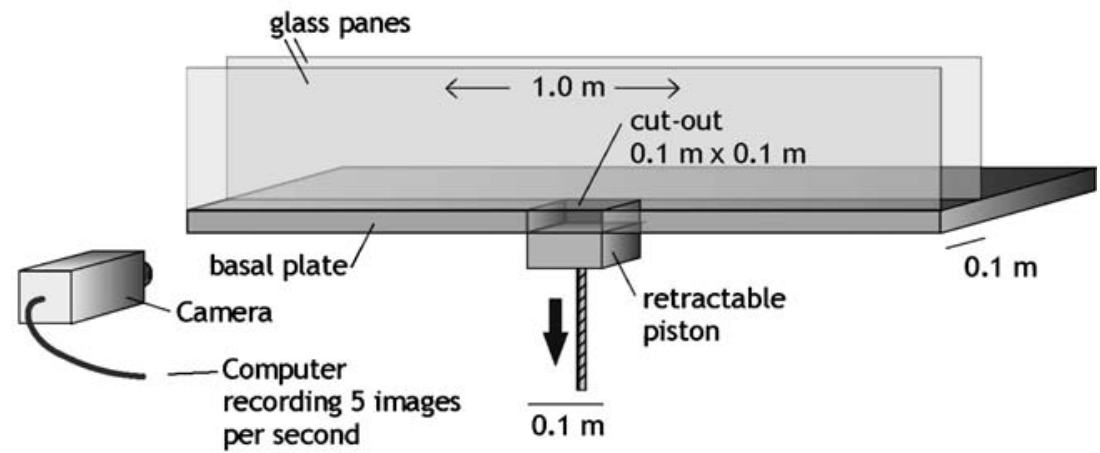

B)

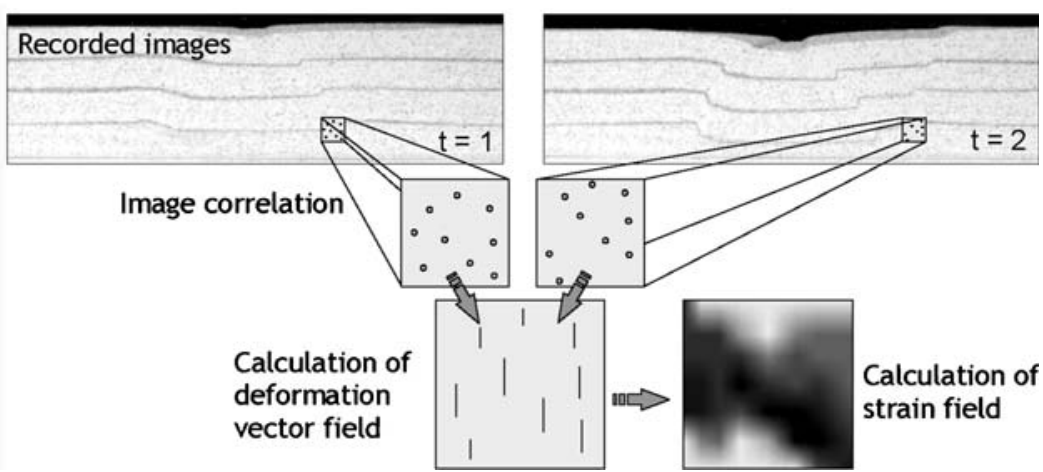

experiment, the piston was located at the level of the basal plate, which was overlain by the analogue crustal material. Using a computer-controlled motor, we set piston retraction at a subsidence rate of $0.015 \mathrm{~cm} \mathrm{~s}^{-1}$ for $120 \mathrm{~s}$, to a total subsidence of $1.8 \mathrm{~cm}$. In systematic experimental tests, we varied the chamber depth to evaluate the influence of the roof aspect ratio (AR), which ranged from 0.41 to 3.01 in eleven individual experiments. This AR range also covers the geometric configuration of the Miyakejima caldera system, to which the results are compared in section "Comparison of experimental structures to Miyakejima chronology".

The experiments were geometrically and partially dynamically scaled (cf. Hubbert 1937; Sanford 1959) to fit the configuration of natural calderas regarding roof aspect ratio and subsidence. The geometric scaling factor was $2.5 \times 10^{-5}$, so that $1 \mathrm{~cm}$ in the experiments corresponds to approximately $400 \mathrm{~m}$ in nature. As a crustal analogue material, we used a 1:5 mixture of wheat starch (cf. Donnadieu and Merle 1998) and dry quartz sand (Cobbold and Castro 1999). We determined the coefficient of internal friction $\mu_{\mathrm{F}}$ for the starch-sand mixture with the ring shear test; the angle of internal friction $\phi_{\mathrm{F}}$ is $\sim 28^{\circ}$ and thus comparable to natural systems. The natural cohesion of crustal materials is in the range of $10^{5}$ to $10^{7} \mathrm{~Pa}$ (e.g. Hoshino et al. 1972), while the cohesion of the analogue material is $70 \mathrm{~Pa}$. Considering a scaling factor of $2.5 \times 10^{-5}$, cohesion in our experiments is thus properly scaled. A comparison of experiments with pure sand and the mixed sand-starch material showed similarly oriented structures, although the structural resolution obtained in the sand-starch mixture is considerably higher and provides additional details. Particulars of ring-shear granular material tests and the scaling procedure are provided in the Electronic Supplementary Material.

Time-dependent viscosities of the magma analogue were not considered in these experiments, since we focused our investigation on brittle fracturing only. Other limitations of our experiments include the simplified geometry, rheology, and sidewall effects. The subsiding magma chamber roof is simulated by a retracting undeformable piston that induced stresses at the base of the overlying roof. In nature, the pressure within the magma chamber should be different from lithostatic, so that the distribution and relative intensity of stresses within the roof could be different from those in the experiment. We note however, that the chamber geometry is in agreement with plutons that are often nearly flat-roofed (e.g. Pitcher 1993, Zak and Paterson 2006). Furthermore, subsidence occurred along panes of glass that might influence experimental results by friction. However, the structures produced during the experiments were the same in the vicinity and away from the glass panes. In addition, our results broadly mimic those of other studies, yielding geometric similarity even though different materials and apparatus were used (cf. Acocella 2008). 
Digital image processing results

From the DIC analysis of the individual experiments, we reconstructed a temporal sequence of fault propagation and interaction. Each experiment simulated up to $\sim 700 \mathrm{~m}$ of subsidence in nature. About 600 successive digital images were recorded for each experiment and postprocessed in order to constrain the structural evolution in detail. A photo sequence showing the computed fault initiation, propagation, and interaction is illustrated in Fig. 5 for a magma chamber roof aspect ratio (AR, ratio depth-to-width) of $\mathrm{AR}=0.6$, and in Fig. 6 for a roof aspect ratio of $A R=1.5$. Supplementary movies of the experiment development are provided in the Electronic Supplementary Material.

For $\mathrm{AR}<1$, shear zones first appear at depth. A first set of outward-dipping reverse faults initiates underground at the sides of the retracting piston (Fig. 5a). These reverse faults propagate in tandem upwards and reach the surface at outward-dips of $\sim 50^{\circ}$ near the surface and $80^{\circ}$ at depth. When they reach the surface after $\sim 0.2 \mathrm{~cm}(\sim 80 \mathrm{~m}$ in nature) of subsidence, a second, steeper reverse-fault set forms and propagates upward, while the first set of faults becomes inactive. Then, in the caldera periphery, extensional fractures commence to propagate downwards and develop into inward-dipping normal faults (Fig. 5h, i). After subsidence of $\sim 0.6$ to $0.7 \mathrm{~cm}(\sim 250 \mathrm{~m}$ in nature) these peripheral normal faults join with the reverse faults at depth (Fig. 5j). This fault linkage affects the activity of the former dominant reverse faults; they become inactive for most of the ensuing experiment duration. Occasionally near-surface segments of the reverse ring-fault reactivate. Overall, however, subsidence exceeding $0.7 \mathrm{~cm}$ is accommodated almost entirely by displacement along faults that are inward-dipping near the surface and subvertical to steeply outward-dipping at depth (Fig. 51).

For roof aspect ratios $>1$, faulting is initially asymmetric, with laterally alternating propagation and activity of individual faults which develop at larger numbers and different scales compared to low-AR calderas (Fig. 6). The period of downsag observed at the surface lasts up to $\sim 0.26 \mathrm{~cm}$ of subsidence, during which a sequence of faulting occurs beneath the surface. First, reverse faults develop near the magma chamber margin at about $0.1 \mathrm{~cm}$ of subsidence in a symmetric fashion (similar as in $\mathrm{AR}=0.6$ experiment; Fig. 6a, b). Then a second, steeper reverse fault develops on one side of the chamber roof (here to the right of the chamber; Fig. 6b) propagating upwards to the center of the magma chamber roof. When another fault on the opposite side of the chamber (here to the left) develops, displacement transfers from the second to the newly formed fault (Fig. 6d). This is the first fault that reaches the surface with a dip of about $30^{\circ}$, increasing to $45^{\circ}$ in the upper part of the chamber roof and then steepening to $70^{\circ}$ for most of the fault length down to its base at the chamber side. Further sets of faults may develop in alternating patterns, broadening the structural caldera diameter at the surface. In general, the simultaneous activity of two successive reverse-fault pairs on each side of the magma chamber is short-lived, so that displacement is generally focused on one reverse-fault pair. With about $1.2 \mathrm{~cm}$ of subsidence (Fig. 6f), the first inward-dipping reverse faults develop at the caldera periphery. A clear propagation direction, however, is not always recognizable; thus, the periphery faults appear to localize contemporaneously over their entire length. Immediately after interlinkage of the normal and reverse ringfault segments, the upper parts of the outward-dipping faults become inactive (Fig. 6i, j). However, at greater subsidence, they can sporadically become reactivated allowing faulting in the upper part of the subsiding roof.

High-AR caldera formation includes a series of reverse ring faults that lead to a continued disintegration of the subsiding piston. Consequently, collapse of high-AR calderas tends to occur in a segmented (piecemeal) fashion, whereas low-AR calderas are characterized by the subsidence of a more or less coherent piston.

Thus, our experiments reveal complexly propagating and interacting ring faults that develop sequentially, which may help explain the chronologic and geometric patterns observed at Miyakejima during the 2000 caldera collapse.

\section{Comparison of experimental structures to Miyakejima chronology}

The 2000 Miyakejima collapse is probably the best instrumentally recorded caldera-forming event, since it was observed in detail at the surface and monitored with many geophysical methods. Seismic activity below the summit was distributed in a $2 \mathrm{~km}$ wide, columnar swarm, the top of which migrated to shallower depths (Fig. 3; Propagation Phase), while the summit of Miyakejima was initially deflating before caldera collapse occurred at the surface on 8 July. Based on the collected data, Geshi et al. (2002) developed a conceptual model for the structural evolution of the collapse caldera including upward propagation of reverse ring faults. Our experimental results bear a striking resemblance to the model by Geshi et al. (2002). With detailed information about the kinematics of ring fault evolution, the experiments contribute to an understanding of events prior to and during collapse in July and August 2000, especially to the Propagation Phase indicated in Fig. 3.

The effective subsidence achieved during the 40 days of caldera formation was 1.6 to $2.1 \mathrm{~km}$. The aspect ratio of the Miyakejima caldera, constrained by a $3 \mathrm{~km}$ deep reservoir and maximum $1.5 \mathrm{~km}$ diameter structural diameter above (Geshi et al. 2002), was about $A R=2.5$. In Fig. 7, results of 

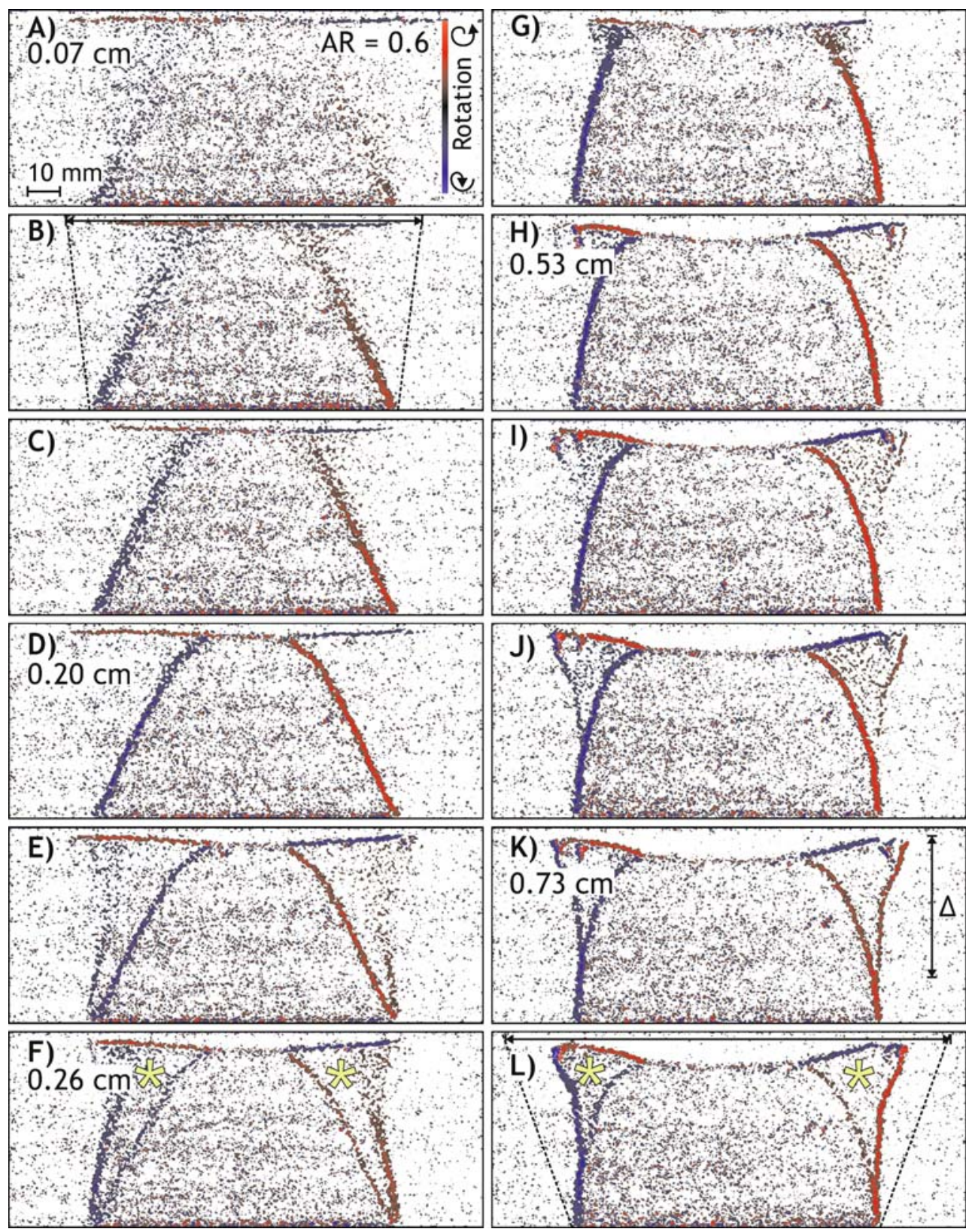

Fig. 5 Sequence of pictures displaying the rotational strain (rotation around the horizontal z-axis) in experiment no. 2D_15-110 with a roof aspect ratio of 0.6 . The rotational strain displays the rotation of individual particles relative to their previous position and can be used to identify the sense of shear of faults (blue $=$ clockwise, red $=$ counter-clockwise rotation). Subsidence is given in $\mathrm{cm}$. The sequence of ring fault evolution starts with upward propagation of a first set of moderately dipping reverse faults followed by a second, outer set that is more steeply dipping. As this set localizes, displacement begins to be transferred from the first set to the second. With around $0.3 \mathrm{~cm}$ of vertical subsidence, accommodation of displacement is entirely

an experiment with $\mathrm{AR}=2$ is illustrated and compared to the development of seismic activity in Miyakejima during the Propagation and Subsidence Phase. Although the scaled subsidence at Miyakejima ( $>40 \mathrm{~mm}$ when scaled down) exceeds the subsidence in our experiments and we

transferred to the outer reverse faults, while the inner faults become inactive. Then normal faults propagate downward and link with the reverse faults at depth $\Delta=4.39 \mathrm{~cm}(\mathrm{~K})$. Further subsidence results in the transfer of the displacement along the normal faults, combined with the lower parts of the reverse faults. The upper parts of the reverse faults only stay sporadically active. Dashed lines in B) and L) illustrate deflection profile of the model surface, while arrows display the limit of influence of caldera subsidence at the surface $(11.7 \mathrm{~cm}$ in B) and $15.0 \mathrm{~cm}$ in L)). Displacement transfer between faults is marked by asterisks. For full videos of experiment 2D_15-110, see Electronic Supplementary Material

neglected the influence of topography, there are clear analogies between our experimental results and caldera collapse at Miyakejima. Similar to the upward-directed propagation of seismicity observed at the volcano (Fig. 3a), our scaled Miyakejima experiments are characterized by 

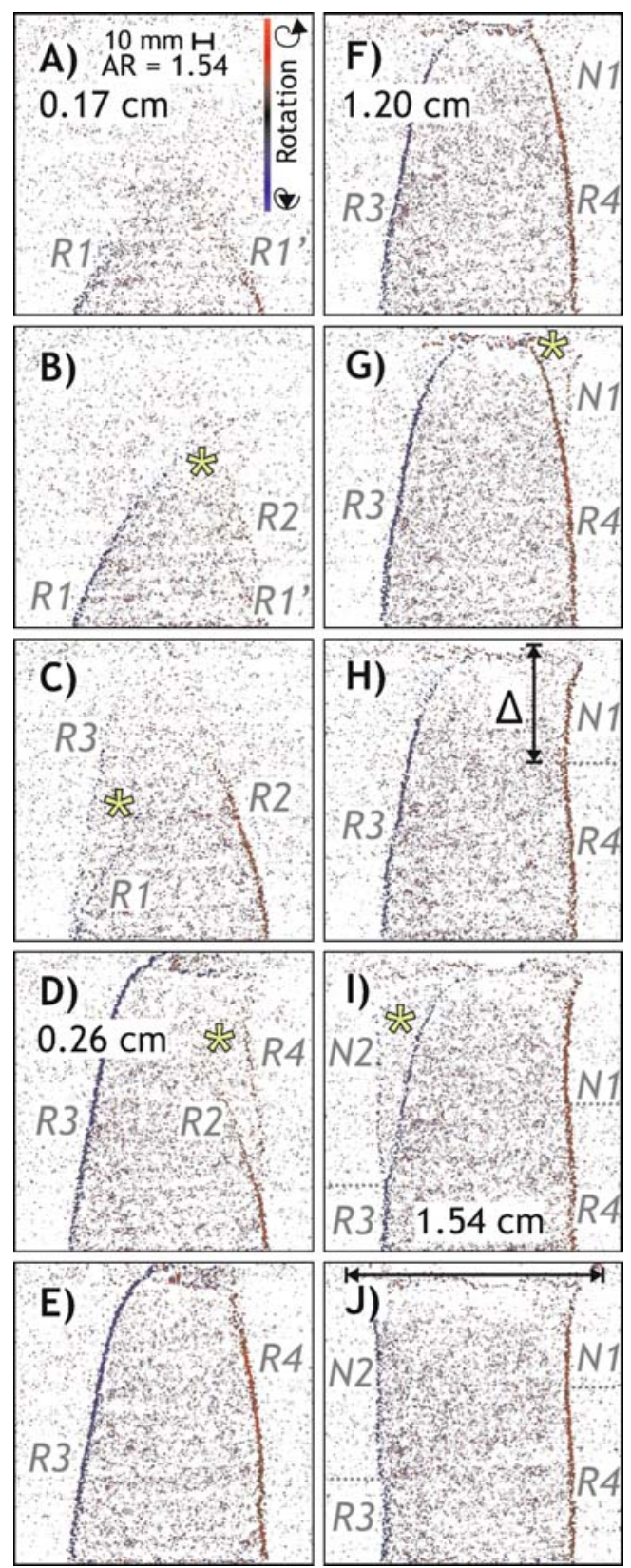

more than three sets of reverse faults that progressively propagate upward to shallower depths so that surface collapse only occurs after subsidence of $4 \mathrm{~mm}$ for $\mathrm{AR}=2$ ( $\sim 160 \mathrm{~m}$ in nature). This sequence of successively active reverse ring faults produced in the experiments for high-AR calderas corresponds to the "stoping column" below the summit of Miyakejima (Geshi et al. 2002), a cylindrical area of underground faulting that could be traced by seismicity before surface collapse occurred. In the experiments, surface collapse is thus delayed relative to magma chamber deflation (cf. Walter and Troll 2001). In the case of Miyakejima, the delay between lateral dike intrusion and surface caldera collapse was 12 days (Geshi et al. 2002; Nakada et al. 2005). In addition, our experimental results
Fig. 6 Sequence of pictures displaying the rotational strain (rotation around the horizontal z-axis) in experiment no. 2D_15-118 with a roof aspect ratio of 1.54. Subsidence is given in $\mathrm{cm}$. Subsidence is accommodated by a complex sequence of ring-fault evolution: a Reverse faults R1 and R1' propagate from the chamber roof upwards and meet at the vertical mid-line of the roof (roof centre). b R2 localizes and propagates upwards until it reaches the roof centre. Displacement transfers from R1' to R2. c R1' becomes inactive, as R2 now takes up all displacement on the model right side (displacement transfer is indicated by an asterisk). R3 localizes and propagates to the roof centre. Displacement begins to transfer from R1 to R3. d R3 reaches the model surface. $\mathrm{R} 1$ has become inactive, as $\mathrm{R} 3$ takes up all displacement on the model left side. R4 begins to propagate upward on the right side. Displacement begins to transfer from R2 to R4. e R2 is inactive, as all displacement on the model right side is taken up on R4, while all left side displacement is taken up on R3. f-h Normal fault N1 propagates downwards and links with R4 at a depth $\Delta$ of $6 \mathrm{~cm}$. Then the upper part of R4 deactivates as near-surface displacement transfers to N1. However, the lower part of R4 remains active. i and j) N2 localizes and links with R3. Displacement transfers from the upper part of R3 to N2, while the lower part of R3 remains active. Thus, the final ring fault configuration is a combination of the lower parts of earlier reverse faults and the later-formed normal faults. The arrow in J) displays the limit of influence of caldera subsidence at the surface $(=13.2 \mathrm{~cm})$. For full video of experiment 2D_15-118, see Electronic Supplementary Material

indicate that with increasing subsidence, larger faults are active and propagate over longer times. This may explain why largest earthquake energy releases did not occur at initial caldera stages, but rather increased during the Propagation and Subsidence Phases on Miyakejima (Fig. 3c). After ring faults have connected to the surface in the experiments, the fault configuration of the inner reverse ring faults remains nearly stable. Furthermore, the experiments show that with increasing subsidence, displacement is transferred from inner reverse ring faults to newly-formed outer normal ring faults (Figs. 5, 6 and 7). This is in accordance with observations at Miyakejima, where the peripheral normal faults play an increasingly important role for successive subsidence after the manifestation of the caldera at the surface (Geshi et al. 2002). In the experiments, the process of displacement transfer is characterized by a transitional phase, during which the peripheral normal faults propagate downward while the reverse faults remain active. The upper segments of the reverse faults become inactive only after the normal faults have linked with the reverse faults at depth (Fig. 6f, j). Hence, the structural diameter of the caldera at the surface increases successively, as was observed at Miyakejima, which increased its diameter by more than $50 \%$ from July to August (Fig. 1). The location of a major normal fault connecting at the base of the present caldera wall outside the initial caldera, as described by Geshi (2009), indicates the outward migration of ring faulting. In the case of Miyakejima, the caldera diameter also increased as a consequence of landslide processes (Geshi et al. 2002). 
Fig. 7 Sequence of events showing the histogram of seismicity and upward trend of location and magnitude as shown in Fig. 3. Pictures displaying the rotational strain (rotation around the horizontal z-axis) in experiment no. 2D 15-120 with a roof aspect ratio of 2.01 , i.e. scaled to Miyakejima volcano. Subsidence is given in $\mathrm{cm}$. Ring faulting involves the formation, upward propagation, and displacement transfer of several successive reverse faults (a-e)

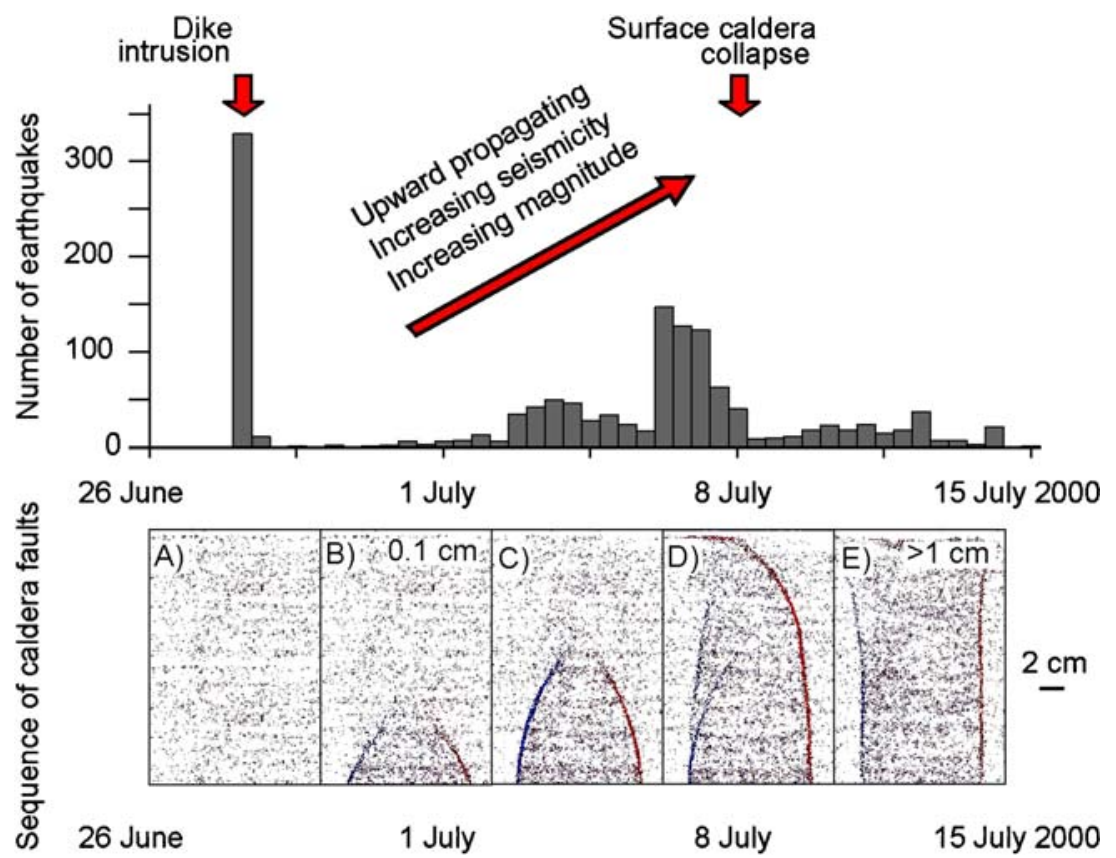

Our experimental results also provide a possible explanation for vent migration and the location of geothermal activity during caldera collapse. According to Geshi and Oikawa (2008), the first phreatomagmatic eruptions at the beginning of collapse occurred near the caldera centre, whereas subsequent eruptions took place at the marginal areas of the caldera. In addition, geothermal activity in the post-caldera stage was concentrated along the rim of the caldera floor. Displacement transfer from inner reverse ring faults that first reach the surface near the centre of the caldera to outer ring faults accompanied by the inactivation of the earlier ring faults, as observed during the experiments, offers a possible explanation for these observations.

\section{Discussion}

The main aim of our experimental study was, with the help of the DIC technique, to analyze and quantify the kinematics of ring faulting during magma chamber deflation. The structural configuration of our experiments reproduced structures observed during earlier experimental studies (e.g. Roche et al. 2000). However, in addition to earlier studies, the DIC results of our models show that the outward-dipping faults initiate at the margins of the magma chamber and propagate in tandem (for low AR), or in alternating sequence (high AR), upwards. In later stages, the inward-dipping ring faults are initiated from surface extension fractures that transform into shear fractures, propagating downwards. Displacement transfer and inactivation of fault segments, as well as linkage, occur between the normal faults and the earlier reverse ring fault; this is considered to be the final structural stage along which most of the successive subsidence occurs.

These findings are, in principal, consistent with earlier conceptual models of caldera collapse (e.g. Branney 1995). However, our experimental results have the advantage that kinematics and timing of individual ring faults can be quantified and that these results can thus be compared to natural examples, such as Miyakejima volcano. Our findings can be applied to other caldera collapse events, such as the 2007 collapse on Reunion Island. Piton de la Fournaise, a basaltic island volcano, similarly showed deflation of a shallow magma chamber, followed six days later by caldera floor subsidence and successive morphologic caldera widening (Michon et al. 2008). Reactivation of existing structural weaknesses may have contributed to the spatiotemporal evolution of the faults.

In general, our observation that caldera ring faults develop in a continuous sequence that explains the multifaceted expression of caldera faults in natural caldera systems, implies that the propagation of the initial ring faults in subsiding calderas can stop, while eruptions may take place along newly-forming sets of peripheral ring faults. This could account for the large widths of many ring-dike complexes, which have previously been explained by stoping (e.g. MacDonald 1972) but are in fact constructed during several magma chamber deflation events with successive ring-dike systems.

Magma transport within upward-propagating ring faults is possible from the initial stages of subsidence. However, the downward-propagating peripheral ring faults can only act as magma feeders if they link to the reverse faults at depth, as our experiments have shown they do. The 
experiments also suggest that magma transport along the initial ring faults may become inhibited due to their closure. Therefore, the temporal variability of the ring faults during subsidence implies that the location of conduits is also temporally variable, tending to propagate outwards, which in turn could explain local stratigraphic discontinuities and inconsistencies. Vent migration, and in some cases vent multiplication during caldera eruptions has been observed, e.g., in Valles, Long Valley, and Santorini (Druitt 1986; Hildreth and Mahood 1986; Self et al. 1986; Holohan et al. 2008). These observations can be interpreted as a consequence of the reconfiguration of the conduit system due to sealing and establishment of magma pathways along a dynamically developing ring fault system.

In a broader sense, an enhanced understanding of the kinematics of ring fault propagation that can be gained from our experimental results may also contribute to better comprehension of caldera-collapse mechanisms, eruption and hazard potential of unrest periods at caldera volcanoes (Scandone and Acocella 2007), magma-chamber dynamics, and interpretation of geophysical monitoring data of calderas, as has been demonstrated for the 2000 caldera collapse at Miyakejima (section "Comparison of experimental structures to Miyakejima chronology"). In addition, ring-fault evolution as a function of subsidence has significance for the location of post-collapse volcanism (e. g. Sierra Negra, Galapagos, Ecuador (Geist et al. 2008)) and geothermal fields (e.g. Goff et al. 2000; Geshi and Oikawa 2008), which are located preferentially along the traces of ring faults at the surface (cf. Scandone and Acocella 2007).

\section{Conclusions}

The formation and evolution of ring faults in collapse calderas were analyzed in a series of scaled analogue experiments. The results were processed with Digital Image Correlation (DIC) and indicate that magma-chamber deflation entails the following sequential evolution of ring faulting:

- During flexure, the first outward-dipping faults develop near the magma chamber margins and propagate upwards in the subsurface.

- For small aspect ratios (shallow and large chambers), reverse ring faults propagate simultaneously, while for high aspect ratios (deep or small chambers) reverse ring faults propagate sequentially.

- During continuous subsidence, new, steeper-dipping reverse faults form outside the earlier-formed faults, and displacement is transferred to the new faults before the earlier ones become inactive. Hence the structural diameter of the caldera widens.

- Normal faults develop from extensional fractures in the zone of maximum extension at the caldera periphery and propagate downwards.

- At depth, the downward-propagating normal faults interact and link with the lower segments of the reverse faults. Consequently, the activity of the upper segments of the reverse faults diminishes.

- The final structural expression of a caldera may be bound by inward- or outward- dipping faults, depending on the amount of subsidence and interaction and linkage of both fault types (cf. Acocella 2007).

Our experimental results provide detailed insights into the kinematics and timing of ring fault evolution that help explain field observations and monitoring data of natural caldera volcanoes. The described sequence of ring fault evolution is useful to the understanding of caldera collapse at Miyakejima volcano in 2000 and other collapse events such as at Piton de la Fournaise in 2007.

Acknowledgements The authors thank Nina Kukowski and Onno Oncken for support and permission to work in the Geodynamic modeling lab, and Matthias Rosenau, Thomas Ziegenhagen, Günther Tauscher, Frank Neumann, Babtiste Scholly, and Nicolas Le Corvec for assistance. St. B. is grateful for financial support from Axel Vollbrecht, and T.R.W. acknowledges financial support by the DFG (WA 1642/1-4). Additionally, the authors thank Nobuo Geshi, Takao Ohminato, and Bogdan Ernescu for organizing and providing seismic data for Miyakejima. Finally, Olivier Roche, Nobuo Geshi, Joan Martí, and an anonymous reviewer are acknowledged for helpful reviews and John Stix for editorial work.

Open Access This article is distributed under the terms of the Creative Commons Attribution Noncommercial License which permits any noncommercial use, distribution, and reproduction in any medium, provided the original author(s) and source are credited.

\section{References}

Acocella V (2007) Understanding caldera structure and development: An overview of analogue models compared to natural calderas. Earth Sci Rev 85:125-160

Acocella V (2008) Structural development of calderas: a synthesis from analogue experiments. In: Gottsmann J, Marti J (eds) Caldera volcanism. analysis, modelling and response. Elsevier, Amsterdam, pp 285-312

Adam J, Urai JL, Wieneke B, Oncken O, Pfeiffer K, Kukowski N, Lohrmann J, Hoth S, van der Zee W, Schmatz J (2005) Shear localisation and strain distribution during tectonic faulting - new insights from granular-flow experiments and high-resolution optical image correlation techniques. J Struct Geol 27:283-301

Branney MJ (1995) Downsag and extension at calderas: new perspectives on collapse geometries from ice-melt, mining, and volcanic subsidence. Bull Volcanol 57:303-318

Cobbold PR, Castro L (1999) Fluid pressure and effective stress in sandbox models. Tectonophysics 301:1-19 
Cole JW, Milner DM, Spinks KD (2005) Calderas and caldera structures: a review. Earth Sci Rev 69:1-26

Donnadieu F, Merle O (1998) Experiments on the indentation process during cryptodome intrusions: new insights into Mount St. Helens deformation Geology 26:79-82

Druitt TH (1986) Vent evolution and lag breccia formation during the Cape Riva eruption of Santorini. Greece J Geol 93:439454

Druitt TH, Sparks RSJ (1984) On the formation of calderas during ignimbrite eruptions. Nature 310:679-681

Folch A, Marti J (2004) Geometrical and mechanical constraints on the formation of ring-fault calderas. Earth Planet Sci Lett 221:215-225

Furuya M, Okubo S, Tanaka Y, Sun W, Watanabe H, Oikawa J, Maekawa T (2001) Caldera formation process at the 2000 Miyakejima volcano detected by spatio-temporal gravity change. J Geogr 110:217-225 (in Japanese with English abstract)

Geist DJ, Harpp KS, Naumann TR, Poland M, Chadwick WW, Hall M, Rader E (2008) The 2005 eruption of Sierra Negra volcano, Galapagos, Ecuador. Bull Volcanol 70:655-673

Geshi N (2009) Asymmetric growth of collapsed caldera by oblique subsidence during the 2000 eruption of Miyakejima, Japan. Earth Planet Sci Lett 280:149-158

Geshi N, Oikawa T (2008) Phreatomagmatic eruptions associated with the caldera collapse during the Miyakejima 2000 eruption, Japan. J Volcanol Geotherm Res 176:457-468

Geshi N, Shimano T, Chiba T, Nakada S (2002) Caldera collapse during the 2000 eruption of Miyakejima Volcano, Japan. Bull Volcanol 64:55-68

Geyer A, Folch A, Martí J (2006) Relationship between caldera collapse and magma chamber withdrawal: An experimental approach. J Volcanol Geotherm Res 157:375-386

Goff F, McMurty GM, Counce D, Simac JA, Roldán-Manzon AR, Hilton DR (2000) Contrasting hydrothermal activity at Sierra Negra and Alcedo volcanoes, Galapagos Archipelago, Ecuador. Bull Volcanol 62:34-52

Gray JP, Monaghan JJ (2004) Numerical modelling of stress fields and fracture around magma chambers. J Volcanol Geotherm Res 135:259-283

Gudmundsson A, Nilsen K (2006) Ring faults in composite volcanoes: structures, models and stress fields associated with their formation. In: Troise C, De Natale G, Kilburn CRJ (eds) Mechanisms of activity and unrest at large calderas. Geol Soc London Spec Pub 269:83-108

Hildreth W, Mahood GA (1986) Ring-fracture eruption of the Bishop Tuff. Geol Soc Am Bull 97:396-403

Holohan EP, Troll VR, van Wyk de Vries B, Walsh JJ, Walter TR (2008) Unzipping Long Valley: An explanation for vent migration patterns during elliptical ring fracture eruption. Geology 36:323326

Hoshino K, Koide H, Inami K, Iwamura S, Mitsui S (1972) Mechanical properties of Japanese Tertiary sedimentary rocks under high confining pressures. Bull Geol Survey Japan 244:1-200

Hubbert MK (1937) Theory of scale models as applied to the study of geologic structures. Geol Soc Am Bull 48:1459-1520

Kennedy BM, Jellinek AM, Stix J (2008) Coupled caldera subsidence and stirring inferred from analogue models. Nature Geosci $1: 385-389$

Lipman PW (1984) The roots of ash flow calderas in Western North America: windows into the tops of granitic batholiths. J Geophys Res 89:8801-8841

Lipman PW (1997) Subsidence of ash-flow calderas: relation to caldera size and magma-chamber geometry. Bull Volcanol 59:198-218
MacDonald GA (1972) Volcanoes. Prentice-Hall, New Jersey

Marti J, Geyer A, Folch A, Gottsmann J (2008) A review on collapse caldera modeling. In: Gottsmann J, Marti J (eds) Caldera volcanism - Analysis, modelling and response. Elsevier, Amsterdam, pp 233-284

Michon L, Staudacher T, Ferrazzini V, Bachelery P, Marti J (2007) April 2007 collapse of Piton de la Fournaise: a new example of caldera formation. Geophys Res Lett 34:L21301. doi:10.1029/ 2007GL031248

Michon L, Villeneuve N, Catry T, Merle O (2008) How summit calderas collapse on basaltic volcanoes: New insights from the April 2007 caldera collapse of Piton de la Fournaise volcano. J Volcanol Geotherm Res 184:138-151

Mori J, McKee CO (1987) Outward-dipping ring-fault structure at Rabaul caldera as shown by earthquake locations. Science 235:193-195

Nakada S, Nagai M, Yasuda A, Shimamoto T, Geshi N, Ohno M, Akimasa T, Kaneko T, Fujii T (2001) Chronology of the Miyakejima 2000 eruption: characteristics of summit collapsed crater and eruption products. J Geogr 110:168-180 (In Japanese with English abstract)

Nakada S, Nagai M, Kaneko T, Nozawa A, Suzuki-Kamata K (2005) Chronology and products of the 2000 eruption of Miyakejima Volcano, Japan. Bull Volcanol 67:205-218

Newhall CG, Dzurisin D (1988) Historical unrest at large calderas of the world. US Geol Survey Bull 1855:1-1108

Pitcher WS (1993) The nature and origin of granite. Chapman and Hall, London

Roche O, Druitt TH, Merle O (2000) Experimental study of caldera formation. J Geophys Res 105:395-416

Sanford AR (1959) Analytical and experimental study of simple geological structures. Geol Soc Am Bull 70:19-52

Sakai S, Yamada T, Ide S, Mochizuki M, Shiobara H, Urabe T, Hirata N, Shinohara M, Kanazawa T, Nishizawa A, Fujie G, Mikada H (2001) Magma migration from the point of view of seismic activity in the volcanism of Miyake-jima Island in 2000. J Geogr 110:145-155 (In Japanese with English abstract)

Saunders SJ (2001) The shallow plumbing system of Rabaul caldera: a partially intruded ring-fault? Bull Volcanol 63:406-420

Scandone R, Acocella V (2007) Control of the aspect ratio of the chamber roof on caldera formation during silicic eruptions. Geophys Res Lett 34:L22307. doi:10.1029/2007GL032059

Schellart W (2000) Shear test results for cohesion and friction coefficients for different granular materials: Scaling implications for their usage in analogue modeling. Tectonophysics 324:1-16

Self S, Goff F, Gardner JN, Wright JV, Kite WM (1986) Explosive rhyolitic volcanism in the Jemez Mountains: vent locations, caldera development and relation to regional structure. J Geophys Res 91:1779-1798

Simkin T, Howard KA (1970) Caldera collapse in the Galapagos islands, 1968. Science 168:429-437

Smith RL, Bailey RA (1968) Resurgent cauldrons. Geol Soc Am Mem 116:613-662

Stix J, Kennedy B, Hannington M, Fiske R, Mueller W, Franklin J, Gibson H (2003) Caldera-forming processes and the origin of massive sulfide mineralization. Geology 41:375-378

Toda S, Stein RS, Sagiya T (2002) Evidence from the AD 2000 Izu islands earthquake swarm that stressing rate governs seismicity. Nature 419:58-61

Tsukui M, Niihori K, Kawanabe Y, Suzuki Y (2001) Stratigraphy and formation of Miyakejima Volcano. J Geogr 156:156-167 (In Japanese with English abstract)

Ueda H, Fujita E, Ukawa M, Yamamoto E, Irwan M, Kimata F (2005) Magma intrusion and discharge process at the initial stage of the 
2000 activity of Miyakejima, central Japan, inferred from tilt and GPS data. Geophys J Int 161:891-906

Walter TR, Troll VR (2001) Formation of caldera periphery faults: An experimental study. Bull Volcanol 63:191-203

Williams H (1941) Calderas and their origin. Bull Dept Geol Sci Univ California 25:239-346

White DJ, Take WA, Bolton MD (2001) Measuring soil deformation in geotechnical models using digital images and PIV analysis. In: 10th International Conference on Computer Methods and Advances in Geomechanics, Tucson, Arizona

Yamaoka K, Kawamura M, Kimata F, Fujii N, Kudo T (2005) Dike intrusion associated with the 2000 eruption of Miyakejima Volcano, Japan. Bull Volcanol 67:231-242

Zak J, Paterson SR (2006) Roof and walls of the Red Mountain Creek pluton, eastern Sierra Nevada, California (USA): implications for process zones during pluton emplacement. J Struct Geol 28:575-587 